\title{
Optimization of hot-air microwave combined drying control system based on air outlet temperature and humidity monitoring
}

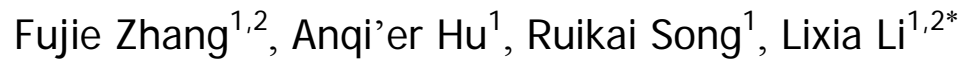 \\ (1. Faculty of Agriculture and Food, Kunming University of Science and Technology, Kunming 650500, China; \\ 2. Mechanization Engineering Research Center of Yunnan Province Colleges and Universities, Kunming 650500, China)
}

\begin{abstract}
Microwave drying is one of the most important drying methods in agriculture. The online measurement and control of material dried, as a challenging research issue, is helping to improve the drying quality of the final product and the energy utilization efficiency of microwave dryers. In order to realize the online measurement of temperature in microwave drying, a detection strategy was based on the temperature and humidity monitoring at the air outlet of coupling hot air and microwave drying method. LabVIEW programming software was employed to collect the temperature and humidity signal value at the outlet of the dryer to estimate the drying degree of the material. According to the amount of moisture removal in real-time, the microwave input power was adjusted gradually in the microwave drying process. Taking potato as material dried, the microwave power of microwave and hot air coupling drying is monitored to realize the real-time regulation. The results showed that the total color difference value of the product of 3.09, the rehydration ratio of 2.92, the unit energy consumption of $17419.35 \mathrm{~kJ} / \mathrm{kg}$, and the drying rate of $0.442 \mathrm{~g} / \mathrm{s}$ were obtained. The minimum comprehensive weighted score of the product was 26.36. Compared with the orthogonal experiment, the optimal drying process was obtained as the total color difference value of the product of 2.84 , the rehydration ratio of 3.01 , the unit energy consumption of $17419.35 \mathrm{~kJ} / \mathrm{kg}$, and the drying rate of $0.397 \mathrm{~g} / \mathrm{s}$. The minimum comprehensive weighted score of the product was 20.67 , and the difference was not significant. The control strategy not only solves the non-uniform phenomenon of drying, and makes the microwave drying real-time and continuous, but also improves the drying efficiency and quality.
\end{abstract}

Keywords: microwave, drying, temperature, humidity, control, power, potato

DOI: $10.25165 /$ j.ijabe.20211404.6366

Citation: Zhang F J, Hu A Q E, Song R K, Li L X. Optimization of hot-air microwave combined drying control system based on air outlet temperature and humidity monitoring. Int J Agric \& Biol Eng, 2021; 14(4): 255-261.

\section{Introduction}

The application of microwave energy has been progressively widely. One of the most critical applications refers to microwave heating, which heats by exploiting the thermal effects of the substance absorbing microwaves. Internal temperature rises and material surface evaporation occur simultaneously. In this regard, it is characterized by a fast drying rate, high efficiency, and low energy consumption. Microwave drying has been broadly applied in the food industry ${ }^{[1,2]}$. However, the complete drying time cannot be accurately predicted because of the fast rate of microwave drying. When the food is dried by microwave for a long time, the quality of the dried product is often degraded due to browning and carbonization. The changes in the internal temperature and moisture content of burdock in the microwave and hot air-coupled drying were studied by Ji et al. ${ }^{[3]}$ The temperature

\section{Received date: 2020-12-21 Accepted date: 2021-03-21}

Biographies: Fujie Zhang, $\mathrm{PhD}$, Associate Professor, research interest: drying technology of agricultural products, agricultural intelligent equipment, Email: 20030031@kust.edu.cn; Anqi'er Hu, Master candidate, research interest: drying technology of agricultural products, agricultural intelligent equipment, Email: hu18830263021@163.com; Ruikai Song, PhD candidate, research interest: drying technology of agricultural products, agricultural intelligent equipment, Email: 313815731@qq.com.

*Corresponding author: Lixia $\mathbf{L i}, \mathrm{PhD}$, Lecturer, research interest: agricultural products processing machinery, biomass materials. Faculty of Agriculture and Food, Kunming University of Science and Technology, 727 Jingming South Road, Chenggong District, Kunming 650500, China. Tel: +86-15911744518, Email: 1ilixia2012@kust.edu.cn. control test was performed by means of the microwave power density and the internal temperature set point of the material was reported, which can shorten the drying time and reduce the deviation of the internal temperature of the material. A hot air drying with the control of relative humidity was proposed by Ju et al. ${ }^{[4]}$ based on the changes of temperature in material processed. The high humidity of hot air in the early drying period notably shortens the drying time. By using the pressure control method, Zhang et al. ${ }^{[5]}$ achieved a continuous adjustment of microwave power in a drying system coupled with thermodynamic microwave with the development of continuously adjustable power. The above-mentioned studies provided the theoretical basis and control strategies for the optimization of the hot-air microwave coupled drying system.

The drying state of the materials is hard to be observed in a microwave drying process. The temperature and humidity in the cavity and the microwave power are the critical factors determining the drying rate and final quality of the materials. Koné et al. ${ }^{[6]}$ adopted a drying method that controls the microwave power density constantly changed, which effectively reduced the temperature of the tomatoes during the drying process and avoided black spots caused by uneven drying. Ju et al. ${ }^{[7]}$ carried out a hot air drying of yam. After drying for $15 \mathrm{~min}$, the relative humidity dropped from $40 \%$ to $20 \%$ and the drying medium temperature reached $60^{\circ} \mathrm{C}$. The temperature-controlled drying method was capable of simultaneously real-time control of the material temperature during the drying process. Accordingly, this reduces the coking phenomenon caused by the high internal temperature of the material ${ }^{[8]}$. Dai et al. ${ }^{[9]}$ found in their study on apricot drying 
kinetics based on temperature and humidity. The drying time with absolute humidity of $65 \mathrm{~g}$ water $/ \mathrm{kg}$ dry air was reduced by $18.75 \%$ compared with the continuous dehumidification controlled trial. Increasing the drying temperature and wind speed or decreasing the absolute humidity both can accelerate the drying rate $^{[10,11]}$. Furthermore, high relative humidity at the initial drying stage can enhance the drying rate and avoid crust formation during hot air convective drying of paddy ${ }^{[12]}$, instant rice noodles ${ }^{[13]}$, and velvet beans ${ }^{[14]}$. This was attributed to the fact that increasing relative humidity at the initial stages can improve the enthalpy of hot air and reduce the internal stress, serving as an additional driving force for moisture diffusion ${ }^{[15]}$. Wu et al. ${ }^{[16]}$ used an infrared hot-air combined dryer based on temperature and humidity control to dry noodles. Tests show that using lower humidity and higher temperature can effectively shorten the drying time. To monitor and control the temperature, humidity, and weight of carrots in the microwave drying process in real-time, Zhou et al. ${ }^{[17]}$ found an adjustable continuity of microwave power by means of LabVIEW software. Therefore, the control strategy of microwave drying will be developed by the microwave power regulation based on changes in temperature and humidity. There is little information available in the literature about monitor the temperature and humidity of the air outlet during the microwave drying process and controlling the microwave power in real-time.

The main objective of this study was to improve the quality of dried products by hot-air and microwave drying systems. So a hot air microwave coupling drying method based on the monitoring of air outlet temperature and humidity was proposed. A coupling hot-air and microwave drying system was designed and installed. The potato was selected as the test material and two different drying strategies were implemented. The first was a drying method without specific microwave power adjusting. The second was microwave power adjusting by monitoring the temperature and humidity at the air outlet. The effects of two kinds of drying on the color, rehydration rate, drying rate, and unit energy consumption of dried potatoes were compared.

\section{Materials and methods}

\subsection{Sample preparation}

Fresh potatoes used in the experiment were purchased from a local supermarket. The potatoes were cut into cubes with a stainless-steel knife as the material to be dried, and $150 \mathrm{~g}$ of samples were used for each experiment. The initial moisture content of the sample was about $81.5 \%$ (w.b.). The material was placed in a self-made drum and placed in a drying test device. The drum was weighed every $3 \mathrm{~min}$; the weight and power consumption of each time were recorded; the moisture content was calculated and the material was weighed until the weight reached a constant value. All experiments were performed in triplicates.

\subsection{Hot-air and microwave combined dryer}

In hot air drying, heat is transferred from the surface of the material to the inside, but microwave drying can directly heat the inside of the material so that a large amount of steam is generated inside the material to form a pressure difference, and the moisture inside the material is quickly removed ${ }^{[18]}$. Hot air and microwave combined drying has a faster drying rate than hot air drying and microwave drying. The structural diagram of the hot air microwave coupling device is shown in Figure 1. This drying system primarily encompasses hot air and microwave generating device. The low noise external rotor centrifugal blower, heating tube, digital PID temperature controller and temperature and humidity sensors are primarily involved. Above the metal mesh (7) is a microwave heating cavity. The microwave generation device is mainly composed of 2M244-M6 magnetrons with a microwave operating frequency of $2450 \mathrm{MHz}$. The magnetron achieves continuously adjustable power by adjusting the switching voltage. The anode operating voltage of $4100 \mathrm{~V}$ and the filament voltage of $3.3 \mathrm{~V}$ is provided by the switching power supply for the magnetron. The microwave power shows an increasing trend with the voltage. The material can be heated more evenly inside the rectangular heating chamber of the device with a dimension of $380 \times 500 \times 360 \mathrm{~mm}$. The roller in the cavity may enhance the uniformity of the dried material. Two magnetrons of this device are located on the back of the cavity and the two feed ports are perpendicular to each other. Accordingly, the coupling power between the two feed ports is comparatively small. Currently, the initial microwave power value can merely be set by a manual knob.

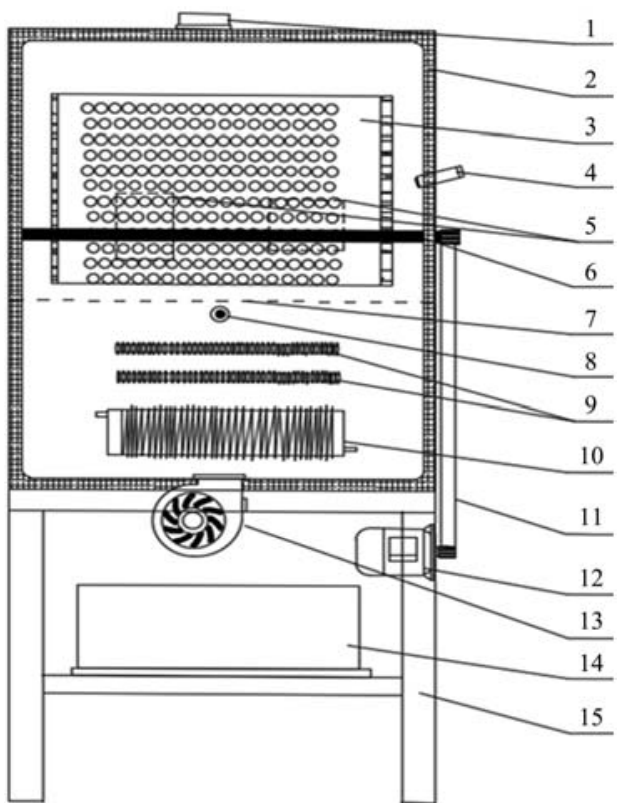

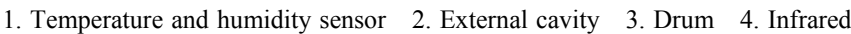
temperature sensor 5. Microwave crater 6. Support roller 7. Metal mesh 8. Temperature sensor 9. Heater 10 Heatsink 11. Belt 12. Drive motor 13. Centrifugal blower 14. Sink 15. Bracket

Figure 1 Schematic diagram of microwave hot air coupling device

\subsection{Experimental procedure}

Two strategies for potato drying were examined.

2.3.1 Strategy 1: No microwave power adjust

Potatoes were dried with fixed microwave power levels $(4 \mathrm{~W} / \mathrm{g}$, $6 \mathrm{~W} / \mathrm{g}, 8 \mathrm{~W} / \mathrm{g}$ and $10 \mathrm{~W} / \mathrm{g}$ ) with hot air at ambient temperature. The wind speed of the fan was adjusted to the third grade (1.4$1.8 \mathrm{~m} / \mathrm{s}$ ). No control of output power was carried out during the process.

2.3.2 Strategy 2: Microwave power adjust based on the monitoring of air outlet temperature and humidity

Potatoes were dried with power level $(4 \mathrm{~W} / \mathrm{g}, 6 \mathrm{~W} / \mathrm{g}, 8 \mathrm{~W} / \mathrm{g}$ and $10 \mathrm{~W} / \mathrm{g}$ ) continuously adjusted was combined with hot air at a constant temperature of $50^{\circ} \mathrm{C}$. The wind speed of the fan was adjusted to the third grade $(1.4-1.8 \mathrm{~m} / \mathrm{s})$. LabVIEW programming software was employed to collect the temperature and humidity signal value at the air outlet of the dryer to estimate the drying degree of the material. According to the amount of moisture removal in real-time, the microwave input power was adjusted gradually in the microwave drying process. 


\section{Calculation of exhaust air volume and moisture discharge capacity}

The drying process of wet material is a coupling process of heat and quality ${ }^{[19]}$. On the one hand, the wet material absorbs heat from the drying medium, and the absorbed heat is transferred from the outside to the inside of the wet material; on the other hand, the moisture inside the wet material is transferred from the inside to the outside, until the water content of the material meets the process requirements. The quality and heat transfer in the drying process are closely related to the environment. The greater the air velocity is, the stronger the moisture absorption capacity of the air, and the faster the saturated humid air accumulated on the surface of the material will be taken away ${ }^{[20]}$. In this experiment, microwave power, hot wind speed and hot air relative humidity were involved as the factors affecting hot-air microwave drying ${ }^{[21]}$. Therefore, the exhaust air volume and moisture exhaust volume of the five-grade wind speed of the hot air microwave coupled drying device were calculated.

3.1 Calculation of exhaust air volume at different wind speeds

The amount of exhaust air was calculated from each grade, respectively. The wind speeds are listed in Table 1.

Table 1 Surface velocity in different series

\begin{tabular}{cccccc}
\hline Grade & One & Two & Three & Four & Five \\
\hline Wind speed $/ \mathrm{m} \cdot \mathrm{s}^{-1}$ & $0.4-0.8$ & $0.9-1.3$ & $1.4-1.8$ & $1.9-2.3$ & $2.4-2.8$ \\
\hline
\end{tabular}

The air outlet is located at the top of the hot air microwave coupling device, as shown in Figure 2. The shaded part refers to the air outlet at the top of the cavity with the size of $350 \mathrm{~mm} \times$ $200 \mathrm{~mm}$. A temperature and humidity sensor was installed at the air outlet and data were collected every $5 \mathrm{~s}$

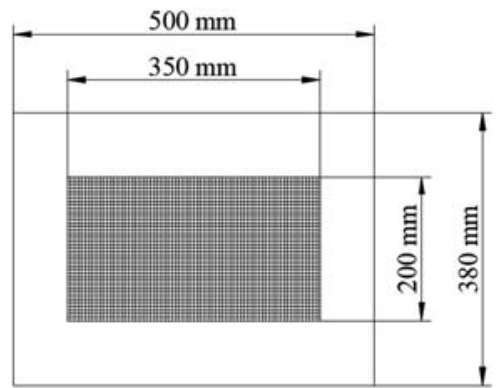

Figure 2 Top exhaust vent of hot air microwave coupling device

The relative humidity and air temperature of the current outlet air were collected and the current absolute humidity was calculated by using the "Absolute Humidity and Relative Humidity Correspondence Table". The exhaust outlet was evenly split into 28 small squares. The wind speed at the center of each small square was measured and superposition was performed to obtain the exhaust per second under the amount of stall when the wind speed at the outlet was not uniform. According to Equation (1), when the wind speed is one grade, two grade, three grade, four grade and five grade, then the amount of exhaust air per second were respectively obtained by Table 2 .

$$
q=S \cdot v
$$

where, $q$ denotes the volume of exhaust air, $\mathrm{m}^{3} / \mathrm{s} ; S$ refers to a small square area, $\mathrm{m}^{2} ; v$ denotes the superimposed wind speed for each stage, $\mathrm{m} / \mathrm{s}$.

Table 2 Exhaust volume at different wind speed levels

\begin{tabular}{cccccc}
\hline Grade & One & Two & Three & Four & Five \\
\hline Exhaust air volume $/ \mathrm{m}^{3} \cdot \mathrm{s}^{-1}$ & 0.042 & 0.077 & 0.112 & 0.147 & 0.182 \\
\hline
\end{tabular}

\subsection{Calculation of moisture loss at different wind speeds}

Common ways to increase the drying capacity include increasing the wind speed of the hot air and reducing the relative humidity of the hot air. After the material is dried, all the evaporated water is taken out by the hot air, and the wind speed of the hot air directly affects the evaporation rate of the material. Increasing the exhaust air volume can reduce the relative humidity of the hot air ${ }^{[22]}$. In the initial stage of actual drying, due to the small water vapor partial pressure difference between the surface of the material and the environment, the drying rate is slow. As the drying progresses, the relative humidity of the air gradually decreases, and the humidity difference between the air humidity and the surface of the material gradually increases, enhancing the evaporation intensity of water ${ }^{[23,24]}$. The moisture removal rate per second is determined by the wind speed. The elevation of the Campus of Kunming University of Science and Technology (Chenggong District, Kunming City, China) is nearly $1951.35 \mathrm{~m}$ with a relative air density of 0.813 , the relative humidity is $\mathrm{RH}=0.69$ and the air temperature is $20^{\circ} \mathrm{C}$ as verified by the data. The relationship between air temperature and air density under standard atmospheric pressure is listed in Table 3.

Table 3 Air density at different air temperatures

$\begin{array}{llllllllllllll}T /{ }^{\circ} \mathrm{C} & -20 & -10 & 0 & 10 & 20 & 30 & 40 & 50 & 60 & 70 & 80 & 90 & 100\end{array}$

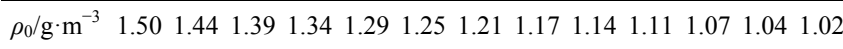

The regression equation for temperature and air density $\rho_{0}$ obtained by fitting is expressed as:

$$
\rho_{0}=1.3873 e^{-0.003 T} \quad R^{2}=0.9961
$$

The law of air density changes with temperature at $1951.35 \mathrm{~m}$ is expressed as:

$$
\rho=0.813 \rho_{0}=1.1279 e^{-0.003 T}
$$

The calculation equation of moisture discharge is as follows:

$$
Q=q_{i} \cdot \mathrm{RH} \cdot \rho
$$

The temperature and humidity sensor at the exhaust outlet is recorded every $5 \mathrm{~s}$. In this regard, based on the foregoing Equations (3) and (4), the relationship between the total amount of humidity and the temperature are collected every $5 \mathrm{~s}$ under different wind speeds, which is calculated as below:

$$
Q=5.635 e^{-0.003 T} q_{i} \cdot \mathrm{RH}
$$

where, $Q$ means humidity, $\mathrm{g} / \mathrm{s}$; $\mathrm{RH}$ denotes relative humidity, $\mathrm{g} / \mathrm{kg} ; q_{i}$ expresses the exhaust volume at different wind speeds, $\mathrm{m}^{3} / \mathrm{s}$.

Table 4 Moisture loss at different wind speed levels

\begin{tabular}{cccccc}
\hline Grade & One & Two & Three & Four & Five \\
\hline Moisture Loss $/ \mathrm{g} \cdot \mathrm{s}^{-1}$ & 0.15335 & 0.28195 & 0.41000 & 0.53850 & 0.66650
\end{tabular}

\subsection{Absolute and relative humidity}

With the increase of air temperature, the highest absolute humidity showed an increasing trend. The relative humidity signal of the air outlet needs to be converted into absolute humidity to accurately reflect the moisture loss rate of the material during the drying process. The regression equation for the air temperature and the maximum humidity determined by fitting, which is expressed as:

$$
P_{\text {wmax }}=4.2558 e^{0.0608 T} \quad R^{2}=0.9988
$$

The conversion relationship between relative humidity and absolute humidity is expressed as:

$$
P_{w}=\mathrm{RH} \cdot P_{w \max }=\mathrm{RH} \cdot 4.2558 e^{0.0608 T}
$$

where, $P_{w}$ denotes absolute humidity, $\mathrm{g} / \mathrm{m}^{3}$; RH represents relative humidity; $P_{w \max }$ refers to the highest absolute humidity, $\mathrm{g} / \mathrm{m}^{3}$. 


\section{Test and optimization control}

\subsection{Orthogonal test results}

The orthogonal experiments of $\mathrm{L}_{9}\left(3^{4}\right)$ were performed by selecting three factors as hot air temperature, microwave power density, and hot wind speed. The analysis of variance in Table 6 shows that microwave power density had a more significant effect on the test results, that is, at a significant level of $\alpha=0.05$, $F_{B}=35.53>F_{(0.05)}=19.00$. While both the hot air temperature and hot air wind speed both had a significant effect on the test results, that is, the $F$-values of hot wind speed and hot wind temperature are both at a significant level of $\alpha=0.1$, $F_{(0.05)} \geq F \geq F_{(0.1)}$. Therefore, merely the impact of microwave power on the drying results should be considered by the optimization control. The weight coefficient of each index was determined following the entropy method by taking color, rehydration ratio, drying rate, and unit energy consumption as evaluation criteria ${ }^{[25,26]}$. The weights of total color difference value, rehydration ratio, drying rate, and unit energy consumption are $0.35,0.19,0.28$, and 0.17 . The comprehensive weighted comprehensive score value of each trial can be calculated by the following equation.

$$
\begin{aligned}
y_{j}= & 0.35 \times \frac{100 \times\left(\Delta E_{j}-\Delta E_{j \min }\right)}{\Delta E_{j \max }-\Delta E_{j \min }}+0.19 \times \frac{100 \times\left[\left(R_{R j \max }-R_{R j}\right)-\left(R_{R j \max }-R_{R j}\right)_{\min }\right]}{\left[\left(R_{R j \max }-R_{R j}\right)_{\max }-\left(R_{R j \max }-R_{R j}\right)_{\min }\right]} \\
& +0.28 \times \frac{100 \times\left[\left(U_{j \max }-U_{j}\right)-\left(U_{j \max }-U_{j}\right)_{\min }\right]}{\left[\left(U_{j \max }-U_{j}\right)_{\max }-\left(U_{j \max }-U_{j}\right)_{\min }\right]}+0.17 \times \frac{100 \times\left(N_{j}-N_{j \min }\right)}{N_{j \max }-N_{j \min }}
\end{aligned}
$$

where, $j=1,2, \ldots, 9 . \quad y_{j}$ is the comprehensive weighted scoring value of test $j ; \Delta E_{j}$ is the total color difference value of test $j ; \Delta E_{j \min }$, $E_{j \max }$ are the minimum and maximum values of total color difference; $R_{R j \max }$ is the maximum value of rehydration ratio; $R_{R j}$ is the rehydration ratio of test $j ;\left(R_{R j \max }-R_{j}\right)_{\min },\left(R_{R j \max }-R_{j}\right)_{\max }$ are the minimum and maximum values of $R_{R j \max }-R_{j}$; $U_{j \max }$ is the maximum drying rate; $U_{j}$ is the drying rate of test $j ;\left(U_{j \max }-U_{j}\right)_{\min }$, $\left(U_{j \max }-U_{j}\right)_{\max }$ are the minimum and maximum values of $U_{j \max }-U_{j}$;
$N_{j}$ is the unit energy consumption of test $j ; N_{j \min }, N_{j \max }$ are the minimum and maximum unit energy consumption.

The comprehensive weighted scores of nine trials were obtained. The lower the score, the better the drying effect will be. The optimal parameters of drying were obtained as hot air temperature of $50^{\circ} \mathrm{C}$, microwave power density of $6 \mathrm{~W} / \mathrm{g}$, and hot air wind speed third grade of (1.4-1.8 m/s), with its comprehensive weighted score value of 20.67 , which are listed in Table 5 .

\begin{tabular}{|c|c|c|c|c|c|c|c|c|c|}
\hline \multirow{2}{*}{$\begin{array}{c}\text { Test } \\
\text { number }\end{array}$} & \multicolumn{4}{|c|}{ Factor } & \multicolumn{4}{|c|}{ Index } & \multirow{2}{*}{$\begin{array}{l}\text { Comprehensive } \\
\text { weighted score }\end{array}$} \\
\hline & $\begin{array}{c}A \text { (Hot air } \\
\text { temperature) } /{ }^{\circ} \mathrm{C}\end{array}$ & $\begin{array}{c}B \text { (Microwave power } \\
\text { density) } / \mathrm{W} \cdot \mathrm{g}^{-1}\end{array}$ & $\begin{array}{l}C \text { (Hot wind } \\
\text { speed }) / \mathrm{m}^{-1} \mathrm{~s}^{-1}\end{array}$ & $\begin{array}{l}\text { Empty } \\
\text { column }\end{array}$ & $\begin{array}{l}\text { Total color } \\
\text { difference }\end{array}$ & $\begin{array}{l}\text { Rehydration } \\
\text { ratio }\end{array}$ & $\begin{array}{c}\text { Drying } \\
\text { rate } / \mathrm{g} \cdot \mathrm{min}^{-1}\end{array}$ & $\begin{array}{c}\text { Unit energy } \\
\text { consumption } / \mathrm{KJ}^{-1} \mathrm{~kg}^{-1}\end{array}$ & \\
\hline 1 & $50(1)$ & $4(1)$ & $1.2(1)$ & (1) & 3.18 & 2.92 & 0.220 & 17419.35 & 44.29 \\
\hline 2 & 50 & $6(2)$ & $1.6(2)$ & (2) & 2.84 & 3.01 & 0.397 & 17419.35 & 20.67 \\
\hline 3 & 50 & $8(3)$ & $2.0(3)$ & (3) & 4.11 & 3.09 & 0.568 & 17419.35 & 32.46 \\
\hline 5 & 60 & 6 & 2.0 & (1) & 4.47 & 2.95 & 0.442 & 23225.80 & 59.13 \\
\hline 6 & 60 & 8 & 1.2 & (2) & 3.91 & 3.13 & 0.611 & 14516.13 & 21.35 \\
\hline 7 & $70(3)$ & 4 & 2.0 & (2) & 3.95 & 2.80 & 0.294 & 37741.94 & 75.25 \\
\hline 8 & 70 & 6 & 1.2 & (3) & 2.97 & 2.97 & 0.442 & 23225.80 & 26.11 \\
\hline 9 & 70 & 8 & 1.6 & (1) & 4.05 & 2.85 & 0.662 & 14516.13 & 32.03 \\
\hline $\mathrm{k}_{1}$ & 32.47 & 63.90 & 30.58 & 45.15 & & & & & \\
\hline $\mathrm{k}_{3}$ & 44.46 & 28.61 & 55.61 & 43.58 & & & & & \\
\hline $\mathrm{R}$ & 18.43 & 35.29 & 25.03 & 6.06 & & & & & \\
\hline
\end{tabular}

Table 5 Orthogonal experimental arrangements and results

Note: (1), (2) and (3) represent the number of levels of each factor.

Table 6 Analysis of variance of orthogonal experimental

\begin{tabular}{cccccc}
\hline $\begin{array}{c}\text { Source of } \\
\text { variance }\end{array}$ & $\begin{array}{c}\text { Deviation sum } \\
\text { of squares }\end{array}$ & $\begin{array}{c}\text { Degree of } \\
\text { freedom }\end{array}$ & $\begin{array}{c}\text { Mean } \\
\text { squares } D_{f}\end{array}$ & $\begin{array}{c}F \\
\text { value }\end{array}$ & Significance \\
\hline$A$ & 524.94 & 2 & 262.47 & 9.03 & $*$ \\
$B$ & 2108.10 & 2 & 1054.05 & 35.53 & $* *$ \\
$C$ & 944.10 & 2 & 472.05 & 15.91 & $*$ \\
Error $e$ & 58.30 & 2 & 29.15 & & \\
\hline
\end{tabular}

Note: $*$ means significant difference $(0.01<P$-value $\leq 0.05)$;** means very significant difference ( $p$-value $\leq 0.01)$.

\subsection{Hot air and microwave drying test}

Figure 3 presents the microwave drying characteristics of potato diced under different microwave power densities. With the increase of the microwave power density, the drying time of the potato dice dropped progressively, as shown in Figure 3a. When the microwave power density exceeds $8 \mathrm{~W} / \mathrm{g}$, potato cubes are prone to coking and browning in the drying process, which affects the quality of potato products. Accordingly, the hot air microwave coupled drying orthogonal test had the microwave power density level of $4 \mathrm{~W} / \mathrm{g}, 6 \mathrm{~W} / \mathrm{g}, 8 \mathrm{~W} / \mathrm{g}$, respectively. The drying stages of potato diced were primarily the speed reduction period and acceleration period, and there was basically no constant speed period, as showed in Figure $3 \mathrm{~b}$. This accordingly indicated that the internal moisture content of the material rapidly decreased, the amount of heat absorbed progressively decreased, the temperature rose slowly, and the temperature difference between the interior and exterior of the potato decreased under microwave drying conditions. That is, the temperature gradient was small, which made it difficult to remove the moisture in the potato $^{[27-29]}$.

The temperature and humidity data collected at the single microwave drying outlet is presented in Figure 4 increased with the increase of the microwave power density. The temperature increased with the drying time. At the end of drying, the 
temperature of the material was also positively correlated with the microwave power density. The power density was positively correlated. The relative humidity at the outlet fell into the rising period and the falling period and the rising period was short, as presented in Figure 4b, where the rising period was in the initial stage of drying. The relative humidity at the outlet increased

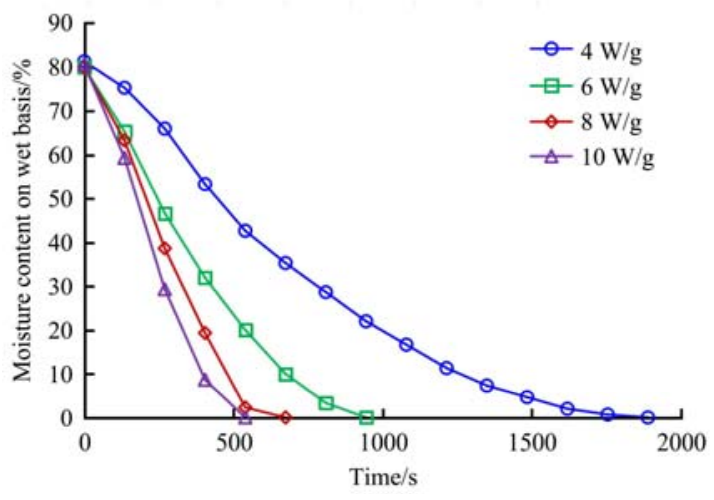

a. Drying curve

under a large amount of free water evaporation of the material. Because the content of free water in the material gradually decreased, the relative humidity of the air outlet was in the decline period. With the increase of microwave power density, the drying time of potato dice was shortened and the curve of relative humidity at the outlet increased.

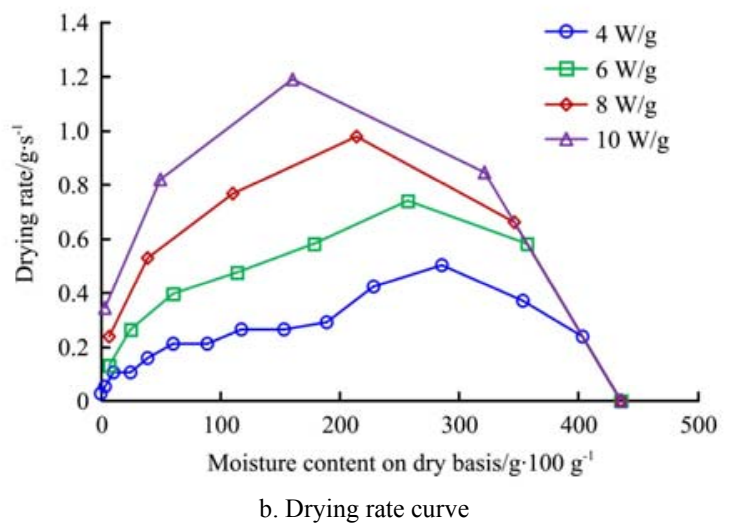

Figure 3 Drying curves and drying rate curves of potato with different microwave power density

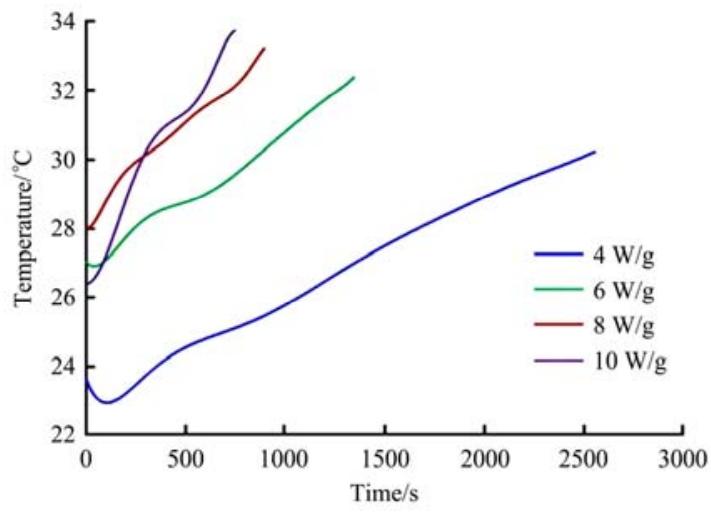

a. Outlet temperature

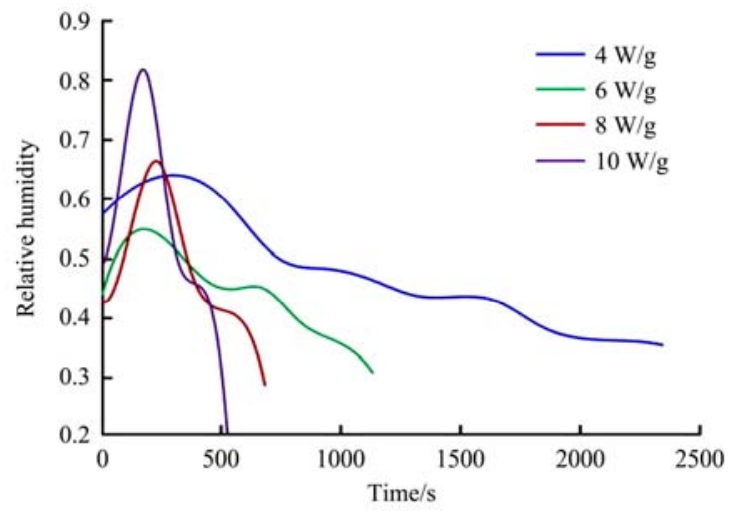

b. Outlet relative humidity

Figure 4 Data acquisition of temperature and humidity at outlet of microwave drying

\subsection{Adjusting microwave power based on temperature and humidity at the air outlet}

Providing a constant drying environment for the material is not necessarily the best drying solution. Sometimes, it not only wastes heat but also causes excessive local drying of the material ${ }^{[30]}$. According to the analysis of variance in Table 6, microwave power density is the most critical factor affecting material drying. Therefore, the microwave power can be adjusted in real-time according to the temperature and relative humidity signals at the air outlet to optimize the control program and obtain high-quality dry products $^{[14]}$. The trends of the amount of moisture discharged under the microwave power densities of $4 \mathrm{~W} / \mathrm{g}, 6 \mathrm{~W} / \mathrm{g}, 8 \mathrm{~W} / \mathrm{g}$, and $10 \mathrm{~W} / \mathrm{g}$, respectively, are presented in Figure 5. The removal rate of moisture first increased and then decreased. The rate of moisture removal also increased with the increase of microwave power density. The humidity was uniform and the rate of moisture removal did not change notably under the microwave power density of $10 \mathrm{~W} / \mathrm{g}$. Under the microwave power density of $4 \mathrm{~W} / \mathrm{g}$, the drying quality of the material was premium, and no burnout or the like occurs, whereas the drying rate was the lowest, the drying time was longer and the energy consumption was also higher, as suggested above. The optimization control program based on the temperature and relative humidity at the outlet was embodied as in the early stage of drying, large microwave power was employed to quickly discharge the free water of the material and the output of the microwave power decreased progressively as time and temperature changed at the outlet.

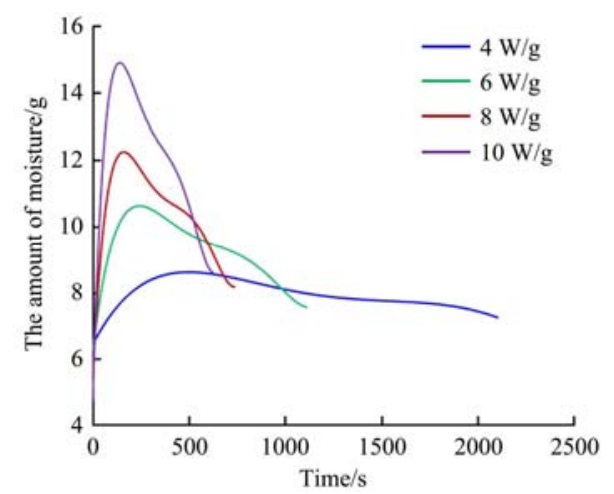

Figure 5 Microwave power density humidity quantity

To provide an anode operating voltage of $4100 \mathrm{~V}$ for the magnetron, the magnetron realizes the power outlet by adjusting the voltage of the switching power supply. The microblog power increases with the increase of the voltage. Seven different microwave power points were selected and the voltage value of the corresponding switching power supply was measured with a multi-meter. The microwave power and the voltage were in a linear relationship, as presented in Figure 6. In this regard, the size of the microwave power can be adjusted by changing the size of the output voltage. The regression equation describing 
microwave power and voltage was fitted as Equation (9):

$$
U=0.0043 P-1.1555 \quad R^{2}=0.9994
$$

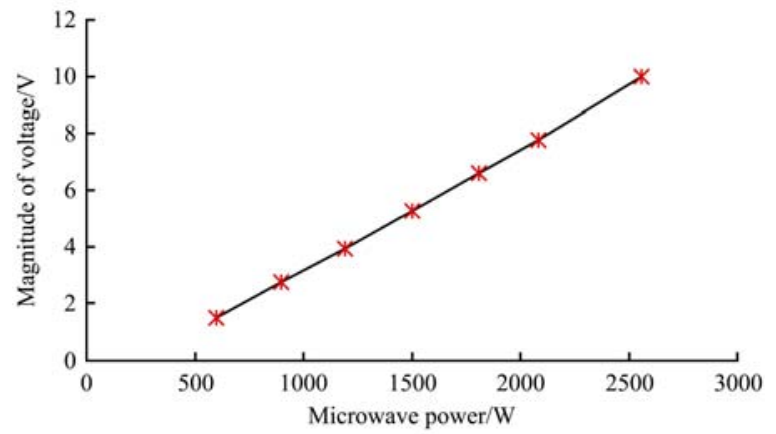

Figure 6 Voltage values under different microwave power

For signal acquisition and real-time adjustment of the size of microwave power, the system employed LabVIEW programming software. The equation to acquire the amount of moisture was introduced into the LabVIEW programming software. Thus, the temperature and humidity signal of each input would eventually be output as the humidity. The value of the corresponding exhaust air volume was introduced in Equation (7) at various wind speed positions. The temperature and humidity sensor of the exhaust outlet recorded the temperature and relative humidity of the current room and calculated the absolute humidity prior to drying. The temperature and humidity signals were collected every $5 \mathrm{~s}$ and the calculated absolute humidity was recorded at the beginning of drying. The amount of water loss when the material dried for every second can be attained. The moisture content of the material in the drying process can be correctly evaluated and the drying stage can be effectively monitored by using this cumulative calculation. It was necessary to control the drying time to avoid over-drying of materials and coking in excess time. The control flow chart for adjusting microwave power based on temperature and humidity monitoring is presented in Figure 7.

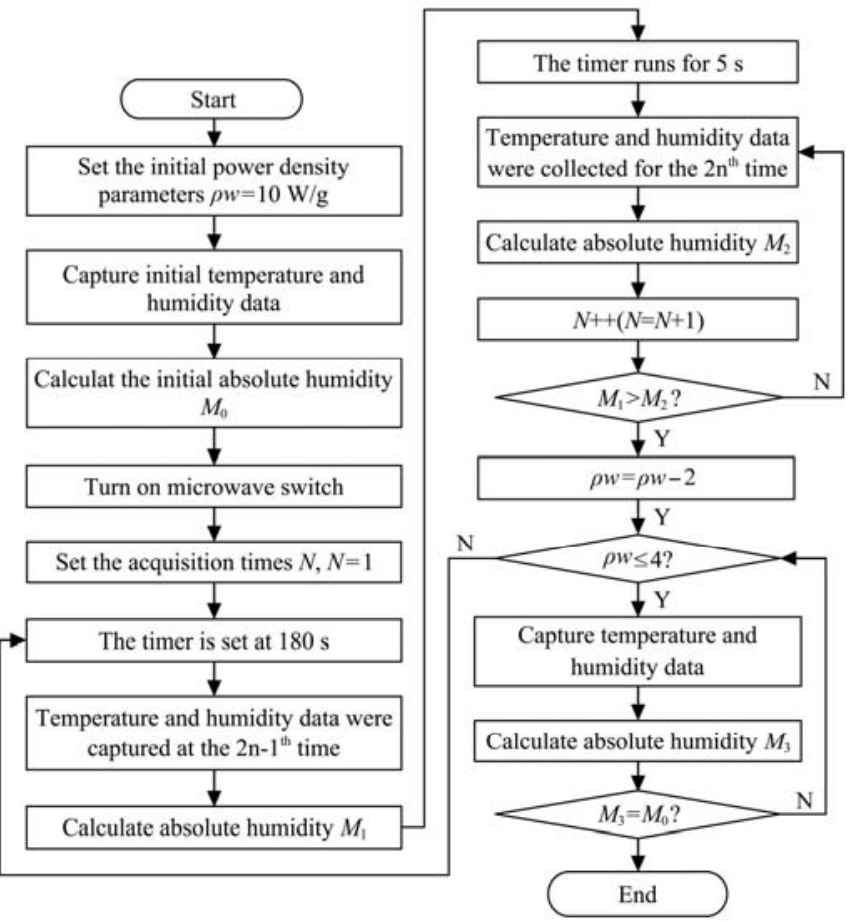

Figure 7 Flow chart of controlling microwave power

At the beginning of drying, the microwave power density was $10 \mathrm{~W} / \mathrm{g}$ and the drying time was $120 \mathrm{~s}$. The initial large microwave power contributed to the rapid decrease of the free water content in the material and a large amount of moisture removal, as suggested from Figure 4. The interior and exterior of the material were heated simultaneously in the microwave drying process. However, the evaporation of water causes a decrease in the surface temperature of the material. Therefore, greater microwave power density consequently improved the internal temperature of the material with a large temperature difference between the inside and the outside, which was not conducive to the removal of moisture. Eventually, the drying rate was declined. The drying process with decreasing microwave power density can ensure that the material had a long acceleration period in the drying process. This adjustment improved the drying efficiency and ensured the drying quality. The temperature and humidity signals at $180 \mathrm{~s}$ and $185 \mathrm{~s}$ were collected and the amount of moisture was calculated during the test. If the dehumidification rate shows a decreasing trend, the microwave power density should be reduced by $2 \mathrm{~W} / \mathrm{g}$ and the drying time remains unchanged at $180 \mathrm{~s}$. Otherwise, the microwave power density and the drying time were inconstant. Loops this logic and sets $4 \mathrm{~W} / \mathrm{g}$ as the minimum power density. Temperature and humidity signals were collected every $1 \mathrm{~s}$ and the absolute humidity value was calculated under the microwave power density of $4 \mathrm{~W} / \mathrm{g}$. Drying is not completed until the absolute humidity value of the output is equal to the initial absolute humidity value. The logic of the dry material with microwave power density progressively decreasing does not notably impact the drying efficiency and prevents coking and browning of the material during the microwave drying process, which ensures the quality of the dried product.

\subsection{Verification experiment}

Adjusting microwave power based on temperature and humidity at the air outlet until the drying was completed and the results of the experiment were evaluated. The result was attained as the product took on the color difference of 3.09 in total, a rehydration ratio of 2.92 , a unit energy consumption of $17419.35 \mathrm{~kJ} / \mathrm{kg}$ and a drying rate of $0.442 \mathrm{~g} / \mathrm{s}$. The final integrated weighted value for the product reached 26.36, while the combined weighted score for the optimal combination of hot air microwave coupled drying experiments reached 20.67, which was a small difference. This illustrated the effectiveness and feasibility of an optimized control program given the temperature and relative humidity at the outlet.

\section{Conclusions}

This study was primarily concerned with a type of hot air microwave coupled drying system which establishes the wind speed of faction into five gears to measure the wind speed of each gear and calculate the corresponding exhaust air. Besides, the relationships among air temperature, air density, and maximum absolute humidity were also discussed.

The microwave drying experiment was performed by selecting potato as the drying object. The microwave drying test results were used to obtain the drying characteristics of the materials in the microwave environment and the signal of the temperature and relative humidity of the air outlet was combined to optimize the microwave power control system of the device. After inputting the equation into LabVIEW, the software helped to adjust the output power. Accordingly, the microwave power suggested a progressive decline in drying. The drying time can be predicted correctly using the hygroscopic value. It is effective to prevent the drying time from lasting too long and leading to the decline of dry product quality. The best drying process obtained by 
orthogonal experiment was that the total color difference of the product of 2.84 , the rehydration ratio of 3.01 , the unit energy consumption of $17419.35 \mathrm{~kJ} / \mathrm{kg}$, and the drying rate of $0.397 \mathrm{~g} / \mathrm{s}$. The minimum comprehensive weighted score of the product was 20.67. Compared to the hot air coupled microwave drying based on temperature and humidity control, the total color difference value of the product of 3.09 , the rehydration ratio of 2.92 , the unit energy consumption of $17419.35 \mathrm{~kJ} / \mathrm{kg}$, and the drying rate of $0.442 \mathrm{~g} / \mathrm{s}$ were obtained. The minimum comprehensive weighted score of the product was 26.36 , with little difference between the two data, indicating the effectiveness and feasibility of the optimized control program based on outlet temperature and relative humidity. Therefore, the hot-air microwave combined drying based on temperature and humidity control has the characteristics of rapidness, safety, economy, and high quality, and has a wide range of application prospects in food drying.

\section{Acknowledgements}

This study was financially supported by the Major Science and Technology Special Fund of Science and Technology Department of Yunnan Province (Grant No. 2018ZF004); Analysis and Test Fund of Kunming University of Science and Technology (Grant No. 2019T20030031)

\section{[References]}

[1] Wang S L. Recent development of microwave power uses in the food processing industry and adopt measures of development at home. Transactions of the CSAE, 1993; 9(1): 43-49. (in Chinese)

[2] Zhang M, Tang J, Mujumdar A S, Wang S. Trends in microwave related drying of fruits and vegetables. Trends in Food Science and Technology, 2006; 17(10): 524-534.

[3] Ji F, Li Z F, Li J, Song F H, Xu W X. Research on characteristics of combined microwave-hot air drying of burdock based on temperature control. Science and Technology of Food Industry, 2015; 36(20): 284-288. (in Chinese)

[4] Ju H Y, Zhao H Y, Yu X L, Zhang W P, Wang H, Gao Z J, et al. Design and experiment of box type hot air drier for fruit and vegetables based on temperature and humidity control. Food \& Machinery, 2020; 36(7): 97-103. (in Chinese)

[5] Zhang B Y, Zhang Z G, Zhang F J. A coupled hot air and microwave drying system with microwave power controlled. Journal of Agricultural Mechanization Research, 2017; 39(7): 240-243. (in Chinese)

[6] Koné K Y, Druon C, Gnimpieba E Z, Delmotte M, Duquenoy A, Laguerre J C. Power density control in microwave assisted air drying to improve quality of food. Journal of Food Engineering, 2013; 119(4): 750-757.

[7] Ju H Y, El-Mashad H, Fang X M, Pan Z L, Xiao H W, Liu Y H, et al. Drying characteristics and modeling of yam slices under different relative humidity condition. Drying Technology, 2016; 34(3): 296-306.

[8] Li Z F, Vijaya Raghavan G S, Wang N, Gariepy Y. Real-time, volatile-detection-assisted control for microwave drying. Computers and Electronics in Agriculture, 2009; 69(2): 177-184.

[9] Dai J W, Rao J Q, Wang D, Xie L. Process-based drying temperature and humidity integration control enhances drying kinetics of apricot halves. Drying Technology, 2015; 33(3): 365-376.

[10] Guo L M, Zhang Q, Zhao X M, Zou S P, Liu L. Study on the drying technology and drying characteristics of solar-dryer for high-quality dried apricot. Xinjiang Agricultural Sciences, 2008; 45(6): 1102-1109. (in Chinese)

[11] Xiao H W, Pang C L, Wang L H, Bai J W. Drying kinetics and quality of
Monukka seedless grapes dried in an air-impingement jet dryer. Biosystems Engineering, 2010; 105(2): 233-240.

[12] Xiong S B, Zhao S M. High temperature and high humidity drying of artificially formed rice. Food Science, 2000; 21(8): 31-33. (in Chinese)

[13] Zhao S M, Liu Y M, Xiong S B, Tan R C. Water diffusion properties of instant rice noodles under high temperature and high moisture drying condition. Journal of Huazhong Agricultural University, 2003; 22(3): 285-288. (in Chinese)

[14] Jia L, Kong J X, Liu Y H, Wu Y, Xiong S B, Zhao S M. Studies on high temperature and humidity drying of velvetbean. Science and Technology of Food Industry, 2011; 33(12): 251-254. (in Chinese)

[15] Zhao S M, Tan R C, Liu Y M, Xiong S B. Mathematical model of instant rice noodles during the high temperature and high moisture drying process. Food Science, 2003; 24(7): 52-54. (in Chinese)

[16] Wu M, Duan H, Wang Z W, Su Y, Zheng Z A, Duan Q. Design and experiment of infrared-hot air combined dryer based on temperature and humidity control. Transactions of the CSAM, 2020; 51(S1): 483-492. (in Chinese)

[17] Zhou H M. Study on microwave drying process of carrot based on humidity controlled method. Master dissertation. Wuxi: Jiangnan University, 2017; 76p. (in Chinese)

[18] Yu H M, Zuo C C, Xie Q J. Parameter optimization for microwave coupled with hot air drying process of hawthorn slices using response-surface methodology. Int J Agric \& Biol Eng, 2015; 8(2): 121-134.

[19] Curcio S, Aversa M, Calabrò C, Iorio G. Simulation of food drying: FEM analysis and experimental validation. Journal of Food Engineering, 2008; 87(4): 541-553.

[20] Li K. Study on dehydration dynamics model and characteristic mechanism for Chinese medicinal materials of rhizome by hot air drying. Master dissertation. Kunming: Yunnan Normal University, 2020; 85p. (in Chinese)

[21] Hui J, Li Z F, Li J, Xu W X. Effect of flow rate on humidity and drying characteristics in microwave drying process. Acta Agriculture Zhejiangensis, 2016; 28(6): 1061-1068. (in Chinese)

[22] Design Department of Shanghai Printing and Dyeing Machinery Factory. Basic knowledge of hot air drying (I). China Dyeing \& Finishing, 1977; 3 21-30. (in Chinese)

[23] Ju H Y, Zhao S H, Mujumdar A S, Zhao H Y, Duan X, Zheng Z A, et al. Step-down relative humidity convective air drying strategy to enhance drying kinetics, efficiency and quality of American ginseng root (Panax quinquefolium). Drying Technology, 2020; 38(7): 903-916.

[24] Liu M J, Wu B G, Pan Z L, Ma H L. Study on the drying characteristics and quality of carrot dices with different drying methods. The Food Industry, 2018; 39(1): 158-163. (in Chinese)

[25] Tao J C, Wu J M. New study on determining the weight of index in synthetic weighted mark method. Systems Engineering-Theory \& Practice, 2001; 8: 43-48. (in Chinese)

[26] Yi L, Yang W, Wang C. Drying conditions and drying model of papaya slices during combined microwave-convective hot air dehydration. Science and Technology of Food Industry, 2017; 38(9): 221-227. (in Chinese)

[27] Shi Q L, Zheng Y Q, Zhao Y. Mathematical modeling on thin-layer heat pump drying of yacon (Smallanthus sonchifolius) slices. Energy Conversion and Management, 2013; 71: 208-216.

[28] Adam F. Drying kinetics and quality of beetroots dehydrated by combination of convective and vacuum-microwave methods. Journal of Food Engineering, 2010; 98(4): 461-470.

[29] Medeni M. Drying shrinkage and rehydration characteristics of kiwifruits during hot air and microwave drying. Journal of Food Engineering, 2001; 48(2): 177-182.

[30] Gong X J. Thermodynamic analysis of heat and moisture transfer and crossing of material drying system. Master dissertation. Lanzhou University of Technology, 2017; 51p. 